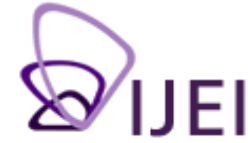

International

Journal for

Educational

Integrity

\title{
"Opening Doors Early to Academic Integrity" - aiding the transition to and managing expectations of academic practice at University
}

\author{
Judith E Jurowska \\ Learning Technologist, Durham University, UK \\ j.e.jurowska@durham.ac.uk \\ John P Thompson \\ Undergraduate Programme Coordinator, Department of Geography, Durham \\ University, UK \\ j.p.thompson@durham.ac.uk
}

A version of this paper was previously included in the International Integrity and Plagiarism Conference Proceedings, Newcastle-upon-Tyne, UK, 16-18 July 2012.

Keywords: academic integrity, plagiarism awareness, critical thinking, transition to university, study skills, managing student expectation

\begin{abstract}
The Geography Department at Durham University has long recognized that Freshers/ newly arrived undergraduate students are suddenly asked to juggle a whole new skills set on arrival at University, often without the level of assistance they have previously experienced at school. As Smith states:

The first year is widely acknowledged as a critical period in determining a students' success at University. However, the period immediately prior to commencing University is also critical. (Smith, 2010, p. 1)
\end{abstract}

This pilot project was designed to help new undergraduate students understand the differences between studying at school and reading for a degree (this British-English term is useful in this context as it refers to a requirement for students to read widely and engage critically with their "major" discipline) and to becoming active participants in a community of practice while at university. Collaboration between the Geography Department, English Language Centre, Learning Technologies and University Library developed a set of discipline specific study skills exercises, based around the concept of Academic Integrity.

The study skills packages were launched within the Virtual Learning Environment (VLE) on September 1, 2011 with an expectation that students would have completed the tasks by mid-October. Answers were collected using the test canvas and students received comprehensive online feedback after they submitted their responses. Postgraduate tutors and module convenors monitoring answers were able to identify areas of concern in terms of student comprehension, powers of analysis and identifying which students had not engaged with the tasks.

The International Journal for Educational Integrity is available online at:

http://www.ojs.unisa.edu.au/journals/index.php/IJEl/

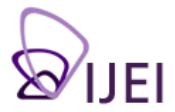


Using data from focus groups with tutors, student surveys and comparison of essay writing performance over past years, we were able to show that cases of recorded plagiarism had fallen to zero saving staff time on plagiarism panels, whilst there was a marked improvement of marks from 2:2 to 2:1 grades.

\section{Introduction}

This paper is based on an on-going pilot project which seeks to aid students make the transition from school to UK university-level study. Prior to arrival at university for the first time in October 2011, some 200+ students were asked to work on a suite of study skills tasks delivered via a secure online learning environment. These tasks and exercises covered a range of skills with the overriding aim of improving standards of academic integrity amongst the undergraduate community. We covered broad topics such as writing effectively, referencing, constructing arguments and also antiplagiarism strategies. The tasks were expected to be completed between the beginning of September and the end of the second week of term, prior to the first formal tutorial meetings. The tasks were designed to take up to six hours in total.

For several years, it has been noticed by staff and postgraduate tutors in the Geography department that student expectations of their university education have been increasing year on year. Coupled with this, UK National Student Survey results and returns from Module Evaluation Questionnaires have demonstrated that students value highly small group contact time with other staff. Comments from past students highlight that their first year at a UK-based University often does not meet their expectations in terms of the amount of training they receive to manage their transition from directed, classroom-led learning to an undergraduate career.

Equally, members of academic staff and research postgraduate tutors have often commented that many newly inducted undergraduate students do not understand the term to 'read for a degree' (this British-English term is useful in this context as it refers to a requirement for students to read widely and engage critically with their 'major' discipline). There is a feeling among staff that there is a widening gulf between the skills and knowledge staff expected undergraduates to come equipped with and those they actually brought to the beginning of their studies.

Both academic and media-based sources have commented on the difficulties faced by students during their first months of their university career. Liz Lightfoot (2006) Education Correspondent of the British-based Daily Telegraph argued that "school pupils are being 'spoon fed' to pass exams instead of being encouraged to develop knowledge and understanding. As a result, they arrive at University expecting to be told the answers" (Lightfoot, 2006). The article then discusses that students often find it difficult to adapt to a system of 'learning and knowing' instead believing that they can continue to 'learn and forget', as they may have been able to adopt at school, when modules are usually broken up into many small numbers of continually assessed components. The pilot project seeks to reverse this surface learning approach and "set the stage properly so that students can more readily use deep approaches to learning" (Biggs \& Tang, 2007, p.31).

Additionally, we have much experience of students struggling to cope with their lecturers/tutors frequent refusals to provide them with a model or the 'correct' answer. It could be argued that model answers rarely exist in the social sciences at undergraduate degree programme level and students are actively encouraged to understand the requirement to develop their own academic voice and have the confidence to write in a critical and reflective manner. 
Our experience confirms the views of Crabtree et al $(2007$, p. 339) that there is a "mismatch between student expectations and experiences" and a "lack of appropriate academic study skills" on entry to university as many of our students find it difficult to come to terms with the independent and self-directed style of university learning (i.e. reading for a degree), and often find the first few months of university study daunting. Additionally, we recognise that students are often expected to demonstrate skills of critical thinking without much in the way of instruction on how to make a successful transition between school and university.

\section{Research Questions}

Our aim was to prepare first year students to enter an academic environment where they would be engaged in their subject and able to uphold and respect academic standards and integrity for the duration of their degree and beyond. We sought to take our project further than Macdonald and Carroll's (2006, p. 236) "not just designed to punish but to 'rehabilitate the offender'" by actively attempting to ensure students would begin their academic career with a firm and all-encompassing grasp of the types of skills which would aid them to avoid poor academic practice and perhaps ultimately falling foul of plagiarism regulations.

This paper therefore seeks to address and consider the following research questions/ themes:

1. To what extent can a set of pre-arrival, online study skills tasks satisfy:

a. student expectation?

b. the challenges of preparing students to 'read' for a degree?

2. We reflect on the manner in which the students engaged with the tasks.

3. We evaluate the success of the pre-arrival online study skills tasks. To this end, we take into account qualitative and quantitative feedback from students and staff, which paints a highly interesting (and complex) picture of student learning behaviour.

The paper concludes with recommendations for further study and additionally seeks to propose improvements to implement for the cohort of students beginning their undergraduate career in late 2012.

\section{Background}

In our experience, plagiarism is a multi-faceted and complex problem which requires both a sympathetic and rigorously enforced set of guidelines. On the one hand, plagiarism is perhaps a result of students not understanding what university-level study involves. This therefore backs up Harvey and Drew's (2006) argument that students may accept the principle of autonomous learning, but need help in becoming autonomous learners. On the other hand, however, Crabtree (2006) argued that some students simply don't (or are unwilling to) engage with the learning process, and are often unaware that independent learning is a requirement for a successful university career.

As Macdonald and Carroll (2006) have argued, Universities have noted a growing awareness of the prevalence of plagiarism, yet often their response has been to focus attention on detection and punishment, rather than to tackle the causes. Our institution (for many years) has made rigorous mention of plagiarism in policy documents (Learning and Teaching Handbooks, Department Undergraduate Guides and so on) yet has not explicitly advertised information relating to belonging to an Undergraduate Community of Practice. Additionally, we have often failed to prioritise 
(and have arguably cut back on) the teaching of study skills during the first few months at university.

Our time-served and extensive experience of students suggests that diverse groups of students exist within our Level 1 (first year) cohort of 222 students. We recognise that whilst all of our students are smart (as evidenced by A-Level or equivalent grades), we also argue that, based on our experience of past cohorts, they can be further subdivided into the following categories:

- $\quad$ Group 1: Smart, keen, and understand what is required to succeed at University (approximately one fifth of our Level 1 intake)

- $\quad$ Group 2: Smart, keen, but require guidance to adapt to their new University career (approximately three quarters of our Level 1 intake)

- $\quad$ Group 3: Smart, but often reluctant (or are unwilling) to grasp independent learning and the need to 'read' for a degree (approximately one in twenty of our Level 1 intake)

Groups 2 and 3 make up a significant proportion of our Level 1 students, and gave a clear indication that action was required. In order to promote principles of academic integrity, we followed certain ideals and concepts outlined by Macdonald and Carroll (2006) and Park (2004). These papers called for the need for a holistic approach to inducting students into their new university career:

- $\quad$ students need skills to aid them to adopt an academic and critical approach to learning

- $\quad$ ensuring that skills development is an integral and ongoing part of the curriculum

- $\quad$ recognise that students are often not equipped for Higher Education when they arrive (Macdonald and Carroll, 2006)

After extensive discussions with staff from the Geography Department, the Learning Technologies Team, the English Language Centre and the Library it was decided that an online package of integrated study skills materials would be created and piloted in September 2011 with all first-year students reading Human and Physical Geography degrees.

Most assignments are already submitted through a plagiarism detection system. However, as Macdonald and Carroll (2006) have advocated, the department felt that this was rather a blunt instrument if that was the only action taken and a more rounded approach encompassing the whole question of academic integrity was required.

The department took as the basis the simple learning principles set out by Moore and co-authors in the Ultimate Study Skills Handbook (2010, pp. 6-7) to design an online pre-arrival study skills package. Undergraduates are expected to take more control of their learning than may previously have been the case, and as such, the package was aimed at encouraging an active approach to learning through questioning, research using media such as podcasts, selected readings from journals and online searches, reflection, together with note taking, time management and essay writing skills. Comprehensive feedback to students was provided via online methods (at time of submission) and via subsequent tutorial sessions. 


\section{Methodology}

As earlier sections of this paper have suggested, we adopted a broad-brush approach to promoting academic integrity and avoiding plagiarism.

The first task for the working group was to ensure that the study skills tasks would provide sufficient depth, but also to ensure that they would provide a sound and transferable base for other Departments in the University (or elsewhere) to use for their own similar purposes.

The wide-ranging team comprised the following:

- Module Convenors for two Level 1 stem courses (Human and Physical Geography)

- Undergraduate Programme Coordinator in the Geography Department

- $\quad$ Learning Technologies Team

- $\quad$ English Language Centre

- University Library

- $\quad$ Postgraduate support from the Geography Department

We began by seeking permission from past students for the project team to use a wide range of their previously submitted essays to assist with the development of the study skills package. Our primary aim in this instance was to provide the English Language Centre with a workable sample of previously submitted work (excellent, good, mediocre and poor essays were considered) in order for their expertise to be used to tap into where our students were making common mistakes. The English Language Centre assisted academic staff and postgraduates from the Geography Department in putting together not only the tasks, but the manner and flavour in which they were to be delivered. The resulting tasks were relatively broad but clearly and simply covered themes of promoting academic integrity and anti-plagiarism strategies in the following ways:

- How to read and take notes effectively

- Using alternative sources in academic essays (for example podcasts)

- How to access online journals and to use their contents successfully

- How to extract main themes/arguments from example texts and how to present these as evidence in a particular argument

- $\quad$ Effective writing - introductions, main body and conclusions

- $\quad$ Plagiarism avoidance

The delivery of the study skills tasks was done via our online learning environment (Blackboard), using dedicated module zones for each task. The tasks were made available to students in early September - five weeks before their arrival. Each part of each task was completed separately; where appropriate a grade was saved to the grade centre, and immediate feedback was provided for each answer. We ensured that certain aspects of the instructions provided easily accessible links to other sources of information, such as online department handbooks, library guides to ejournal access zones and so on. First, we asked students to complete the tasks in a required order, although it was made clear to them that it would be possible to save responses and complete the tasks over a period of time.

We advertised that the tasks would be available to students throughout their first year at University. Whilst we required completion before their first tutorial for each of the Human and Physical Geography modules, students were permitted to return to the 
online tasks whenever they wished to either take part in them again, or simply to revisit the feedback they received during September or early October.

Given topical concerns raised by internal Department quality control mechanisms, and on-going trends identified from the National Student Survey returns, we ensured that feedback was a key theme to the study skills tasks. As mentioned above, online feedback was offered electronically wherever possible. For the large part this comprised of a few sentences or a short paragraph informing students of 'model' answers, or alternatively links to other sources of information was offered.

Postgraduate tutors were briefed comprehensively about the importance of verbal feedback and were required to spend time in their first tutorials (groups of seven) discussing the tasks in detail with their students. We specifically asked the postgraduates to use actually submitted answers by their own students to stimulate discussion. Blackboard allowed each tutorial group to have a separate area in the grade centre for each module, allowing easy access to individual answers and trends in a particular group.

As we have demonstrated, our method here is similar to that followed by University College London (Angelini, 2007). We wanted to ensure that our pre-arrival study skills exercises were wholly and recognisably embedded in the overall programme of Level 1 study. We also sought to provide integrated pre-arrival instructions to students, ensuring that items such as module choices/registration information and so on also provided mention of the requirement (and the academic benefit) to complete the pre-arrival tasks in advance of travelling to University.

We deliberately ensured that the key message of the pre-arrival tasks was one of promoting academic integrity. We were very careful not to over-use the term 'plagiarism'. Even the dedicated section relating to plagiarism had an overriding positive message of promoting sound and professional working practices. Our theme can be summed up by Park (2004 p. 297) as follows: "the academic enterprise is rooted in a culture of integrity, founded on honesty and mutual trust, and a university should expect all of its members (including undergraduates) to respect and uphold these core values".

Students are also required to consider a section of our Undergraduate Guide which relates to the promotion of the Undergraduate Commitment. This is a series of positive statements which seek to get students 'on-side' and realise that diligent, principled academic work will come naturally to them if a certain culture of work is adopted and practiced. As well as being clear and firm that dishonesty/academic malpractice are mendacious and that the Department promotes a culture of peer disapproval of dishonest working practices (Gerdeman 2000, cited in Park 2004), we were equally keen to ensure that the study skills exercises were sold to students as being a positive mechanism which would aid their transition to University life and their goal to become a junior academic, without making them fearful of their new educational challenge.

Finally, we wanted students to realise that support networks available to them come in many different forms. We were therefore very clear to them that the online study skills packages would add and supplement what the Department already offers as a matter of course during the first year of study (for example frequent meetings with academic advisors, academic tutors and availability of senior support staff). 


\section{Findings}

Out of a cohort of 222 students, $95 \%$ participated fully in the study skills tasks. We analysed student responses to the tasks and student feedback on these was sought via a comprehensive online survey. This section seeks to correlate this analysis with in-depth feedback from teaching staff and postgraduate tutors who are well qualified to provide academic judgement on the effectiveness and success of the study skills tasks.

\section{Data from the pre-arrival tasks in the Online Learning Environment}

One of the tasks set for the students was to listen to and read the information provided and then write a short answer to the question "Is the food crisis due to shortages of food or some other cause?". There were a total of 204 students who completed this task with some students taking more than one attempt at the answer making a total of 236 attempts. The length of the answer varied between just 2 words to over 1,000 words, with the average word count being 236 .

It was clear from this one task that there was a wide variation in previous experience of essay writing requirements. A small number of students (4\%) were clearly aware of the standard required and were citing sources and providing a reference list at the end of their work from the outset as shown in the example below:

The issue of storage applies mostly to developing countries, where " $30 \%$ of crops and $40 \%$ of fruit and vegetables are lost due to lack of adequate storage facilities" (De Schutter, 2011).

De Schutter, O. (2011). 'Food crises: five priorities for the G20' The Guardian [Online] Accessed 29/09/2011

Some submissions $(13 \%)$ showed that the need to include referencing was understood but the format or amount of detail required was not:

For example, "in developing countries, $30 \%$ of crops and $40 \%$ of fruits and vegetables are lost because of lack of adequate storage facilities" (De Schutter, Olivier (2011) Food crises: five priorities for G20 (Internet). Available from http://www.guardian.co.uk/global-development/poverty-matters/2011/jun/16/ food-crises-five-priorities-g20. Accessed 24/09/11)

The rest of the submissions appeared to be using evidence from the sources but not acknowledging the original source, as in the following example:

It has also been suggested that the price rises associated with the food crisis can be related to increased energy prices which is obviously a significant factor in the production and harvesting of food, especially given how much machinery is now used in the agricultural industry.

Very few submissions gave no evidence or explanation.

In a separate task, students were tested on their understanding of basic terms using a multiple choice quiz. The quiz was completed by 211 students and $97 \%$ correctly identified that literature refers to the key research that has been produced on a particular topic area. The majority of students (98.5\%) understood that an academic 
argument/debate refers to an issue under discussion within the academic community, that there may be multiple theories, views or approaches to a particular problem and that evidence refers to data or examples you use to support the points you make within a piece of writing.

A follow-on task posed several questions on the theme "Why do we write essays on physical geography?". Students were asked to select the most appropriate answers (Yes/No/Maybe). This task was answered by 209 students who made 289 attempts at the quiz. The expected answer is shaded in Table 1:

Table 1

Why do we write essays?

\begin{tabular}{|l|c|c|c|c|}
\hline $\begin{array}{l}\text { We write essays on physical geogra- } \\
\text { phy.... }\end{array}$ & Yes & No & Maybe & $\begin{array}{c}\text { Un- } \\
\text { answered }\end{array}$ \\
\hline $\begin{array}{l}\text { To find the correct answer to the ques- } \\
\text { tion }\end{array}$ & $7.18 \%$ & $\begin{array}{c}69.38 \\
\%\end{array}$ & $\begin{array}{c}23.45 \\
\%\end{array}$ & $0 \%$ \\
\hline $\begin{array}{l}\text { To show you understand key theories, } \\
\text { ideas and issues within the field }\end{array}$ & $\begin{array}{c}97.61 \\
\%\end{array}$ & $0.96 \%$ & $1.44 \%$ & $0 \%$ \\
\hline $\begin{array}{l}\text { To show you have read widely on the } \\
\text { subject area }\end{array}$ & $\begin{array}{c}73.21 \\
\%\end{array}$ & $8.61 \%$ & $\begin{array}{c}17.70 \\
\%\end{array}$ & $0.48 \%$ \\
\hline $\begin{array}{l}\text { To show you have read everything on } \\
\text { the reading list }\end{array}$ & $\begin{array}{c}2.39 \% \\
\text { (n) }\end{array}$ & $\begin{array}{c}88.04 \\
\%\end{array}$ & $8.61 \%$ & $0.96 \%$ \\
\hline $\begin{array}{l}\text { To show that you have a unique insight } \\
\text { into the question }\end{array}$ & 38.28 & 25.84 & 35.41 & $0.48 \%$ \\
\hline $\begin{array}{l}\text { To show you can use the reading to } \\
\text { shape your answer to the question }\end{array}$ & 87.56 & $2.39 \%$ & $9.57 \%$ & $0.48 \%$ \\
\hline $\begin{array}{l}\text { To show that you are aware of areas of } \\
\text { debate and research in the subject area }\end{array}$ & 96.65 & $0.96 \%$ & $2.39 \%$ & $0 \%$ \\
\hline $\begin{array}{l}\text { To show you are able to take a position } \\
\text { in a debate and research within the sub- } \\
\text { ject area }\end{array}$ & 89.00 & $1.44 \%$ & $9.09 \%$ & $0.48 \%$ \\
\hline $\begin{array}{l}\text { To demonstrate clear understanding of } \\
\text { academic writing conventions }\end{array}$ & 78.47 & $6.22 \%$ & 15.31 & $0 \%$ \\
\hline $\begin{array}{l}\text { To show you can create a coherent, fo- } \\
\text { cused piece of writing }\end{array}$ & 91.39 & $1.91 \%$ & $6.70 \%$ & $0 \%$ \\
\hline
\end{tabular}


Students were then asked questions relating to the characteristics of a successful essay. A total of 184 students completed this quiz taking 245 attempts as in Table 2.

Table 2

Characteristics of a successful essay

\begin{tabular}{|l|c|c|c|}
\hline & True & False & It depends \\
\hline A successful essay always uses complex aca- & $\begin{array}{c}10.33 \\
\%\end{array}$ & $\begin{array}{c}39.67 \\
\%\end{array}$ & $50 \%$ \\
demic language & 22.83 & 60.33 & $16.85 \%$ \\
\hline A successful essay references lecture notes to & $\%$ & $\%$ & \\
support key points & $\begin{array}{c}\% 5.65 \\
\%\end{array}$ & $0 \%$ & $4.35 \%$ \\
\hline A successful essay uses evidence from the liter- & & \\
\hline $\begin{array}{l}\text { A successful essay describes all the relevant } \\
\text { theories in detail }\end{array}$ & 34.78 & $25 \%$ & $40.22 \%$ \\
\hline $\begin{array}{l}\text { A successful essay describes and applies key } \\
\text { theories }\end{array}$ & 94.02 & $0 \%$ & $5.98 \%$ \\
\hline A successful essay shows when literature has & 97.83 & $1.09 \%$ & $1.09 \%$ \\
been drawn upon by giving references & $\%$ & & \\
\hline
\end{tabular}

Finally, students were supplied with five variations of paragraphs from a single internet source. These paragraphs were written as examples of acceptable paraphrasing and referencing, and varied degrees of plagiarism (from flagrant cheating to naïve paraphrasing without suitable referencing). Students were then asked to determine which of these variations would be considered plagiarism (and why) and which would be acceptable for use in an academic essay. A total of 195 students completed this task taking 244 attempts. The results were highly variable as shown in Table 3 (the expected answer is shaded):

Table 3

Identification of example paragraph as plagiarism or not plagiarism

\begin{tabular}{|l|l|l|l|l|l|}
\hline Answer & Q.1 & Q.2 & Q.3 & Q.4 & Q.5 \\
\hline PLAGIARISM: Direct copying with no referenc- & 20 & 14 & 18 & 15 & 18 \\
ing ('flagrant' plagiarising) & $\%$ & $\%$ & $\%$ & $\%$ & $\%$ \\
\hline PLAGIARISM: Direct copying with referencing & 19 & 27 & 15 & 18 & 16 \\
& $\%$ & $\%$ & $\%$ & $\%$ & $\%$ \\
\hline PLAGIARISM: Paraphrasing but no referencing & 22 & 23 & 25 & 18 & 18 \\
& $\%$ & $\%$ & $\%$ & $\%$ & $\%$ \\
\hline PLAGIARISM: Inadequate paraphrasing with & 18 & $7 \%$ & 16 & 13 & 14 \\
referencing & $\%$ & & $\%$ & $\%$ & $\%$ \\
\hline NOT PLAGIARISM: Paraphrasing and referenc- & 15 & 17 & 15 & 23 & 17 \\
ing & $\%$ & $\%$ & $\%$ & $\%$ & $\%$ \\
\hline NOT PLAGIARISM: Direct quotation and refer- & $1 \%$ & $4 \%$ & $2 \%$ & $4 \%$ & $8 \%$ \\
encing & & & & & \\
\hline Unanswered & $6 \%$ & $8 \%$ & $10 \%$ & $9 \%$ & $9 \%$ \\
\hline
\end{tabular}


Students were required to submit and print their answers (including justifications) for discussion during their first tutorial. We anticipated that students would find this part of the task challenging (this contention is backed up by the results set out above) and therefore deliberately did not give any electronic feedback at the point of submission. This required tutors to explore the complex issues relating to the use of academic sources, referencing, paraphrasing and plagiarism via in-depth dialogue in a small group situation. This encouraged discussion in real detail about the often-imprecise borders between acceptable and non-acceptable academic practice. Students appreciated this extra debate with tutors and their peers as it aided their understanding that conforming to the acceptable boundaries of academic research is often a blurred, multifaceted and much-debated set of concepts.

\section{Feedback from Students}

To collate student feedback on the study skills exercises we conducted an extensive online survey (utilising both quantitative and qualitative responses) at the end of the second term, concerning their understanding of academic integrity/plagiarism. The response rate was $32 \%$. This was low, but we argue that the data is valid as a wide range of opinions were expressed with rich qualitative data in evidence.

Question: I understood the terms of "academic integrity" and "plagiarism" before I arrived at University:

\begin{tabular}{|l|l|}
\hline Yes: & $50.8 \%$ \\
\hline No: & $14.3 \%$ \\
\hline I wasn't sure: & $34.9 \%$ \\
\hline
\end{tabular}

Question: The study skills exercises helped me understand the importance of striving for academic excellence and avoiding falling foul of plagiarism regulations:

\begin{tabular}{|l|c|}
\hline Strongly agree: & $9.5 \%$ \\
\hline Agree: & $77.8 \%$ \\
\hline Undecided: & $7.9 \%$ \\
\hline Disagree: & $4.8 \%$ \\
\hline Strongly disagree: & $0.0 \%$ \\
\hline
\end{tabular}

Question: The study skills exercises aided my ability to construct critically-informed arguments in written essays:

\begin{tabular}{|l|c|}
\hline Strongly agree: & $4.8 \%$ \\
\hline Agree: & $41.3 \%$ \\
\hline Undecided: & $25.4 \%$ \\
\hline Disagree: & $25.4 \%$ \\
\hline Strongly disagree: & $3.2 \%$ \\
\hline
\end{tabular}


Question: Which other sources of help did you utilise to aid your study skills during the course of this academic year?

\begin{tabular}{|l|c|}
\hline Academic tutor (outside of formal tutorial times): & 25 \\
\hline Academic advisor: & 15 \\
\hline Feedback: & 52 \\
\hline Online sources: & 37 \\
\hline Study guide books: & 8 \\
\hline Returning to the duo-based study skills exercises as a refresher: & 24 \\
\hline Other (please specify): & 6 \\
\hline
\end{tabular}

Other sources specified were other students, the tutorials and hand-out sheets.

\section{Feedback from Staff}

The tutorials and marking associated with the study skills exercises were carried out by research postgraduates in the department with the marks being moderated by lecturers.

The tutors reported that tutorials were more focused and productive than in previous years with students being more engaged from the outset. Tutors also reported a substantial difference in referencing and use of critical arguments than in previous years. One tutor's comments echo those of other tutors:

My general impression on the effectiveness of the Level 1 study skills exercises is that they have enabled the students to progress at a faster rate - acting on the need to read widely earlier, learning basic academic 'chores' earlier (here I am thinking of referencing in particular), and grasping the differences with Alevel demands earlier (i.e. the need to go beyond the stringing together of facts). Sean Knox, Postgraduate Tutor

Figures 1 and 2 below show a comparison of the results of students' first summative essays from the past three years (2009: 204 students, 2010: 206 students, 2011: 222 students). There is an increase in the percentage of students who would be expected to get first degrees for the Human Geography module but no corresponding increase in the Physical Geography module. Further analysis of the causes of these results would be useful as it is the same cohort of students for each course. 
Figure 1

Comparison of Human Geography assessment results

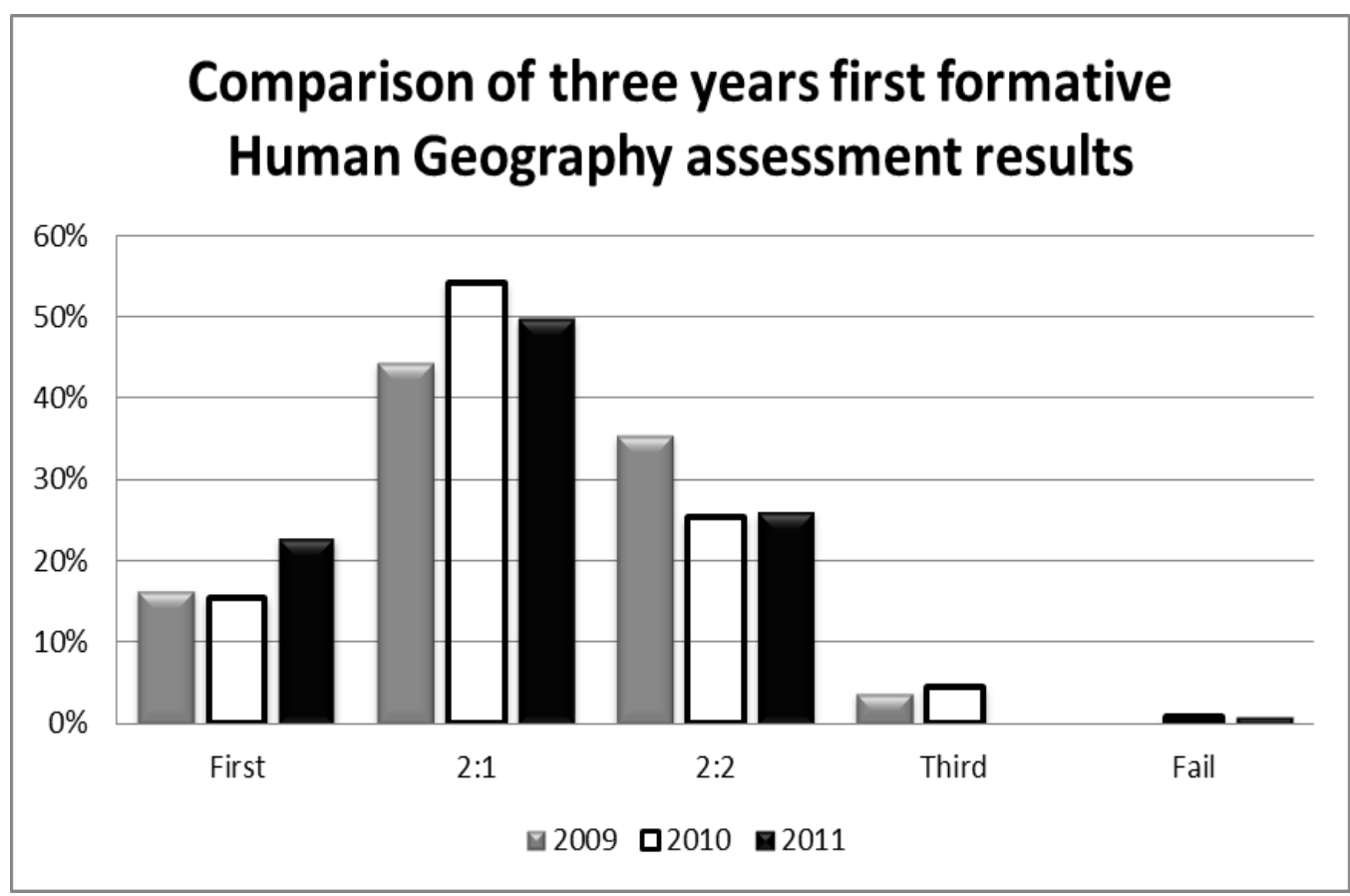

Figure 2

Comparison of Physical Geography assessment results

\section{Comparison of three years first formative Physical Geography assessment results}

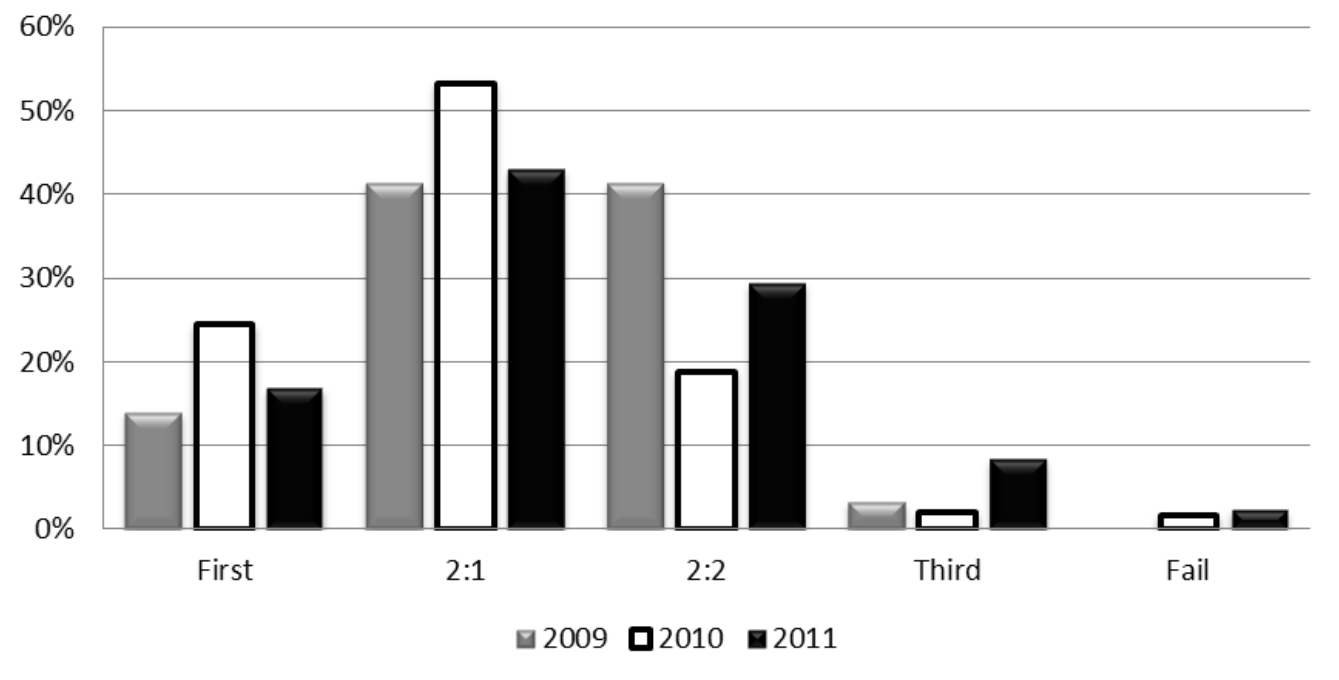


When the marks for the first formative and summative essays for each cohort (Human Geography and Physical Geography) were compared to determine whether the feedback for the formative essay had made any difference to the marks awarded for the summative essay the results showed that in $50 \%$ of students marks had not improved significantly.

On the essays submitted to date (during this academic year), no plagiarism boards have so far been required or convened. There was not even an instance where module staff (including postgraduate markers) raised any concern regarding naïve or 'derivative' essays recommended for further inspection by the Chair of the Board of Examiners.

\section{Discussion}

This project sought to put into practice the holistic institutional approach to academic integrity advocated by Macdonald and Carroll (2006) by preparing undergraduates for higher education prior to entering university.

The tasks undergraduates were required to complete before the start of their studies indicated that while most students understood the need not to plagiarise, they did not fully appreciate its place within the wider context of being a responsible participant within the academic community.

According to the online survey results, $50 \%$ of students who responded indicated that they understood the terms plagiarism and academic integrity prior to arriving at University. However, very few students indicated the sources they were using in their responses to the short answer tasks. This indicates that rigorous citing and referencing sources was not yet 'second nature'. It would appear from the comments of the tutors that students had benefitted from the tasks and had quickly understood the need to build their arguments on the work of others with correct acknowledgement of all sources. This is borne out by the marks for the formative and one summative essay.

The results of the basic terms assessment were very encouraging in that very few students $(<3 \%)$ did not understand the necessity of using literature to research the topic and the need for strong academic arguments or debate backed by solid evidence when writing essays.

It was remarkable that $97 \%$ of students were clear that essays on physical geography are written to show understanding of key theories, ideas and issues, areas of debate and research within the field, all of which have to be correctly referenced.

The most interesting issue in the results for questions on "why essays are written in physical geography?" came out of the question "We write essays on physical geography to show that you have a unique insight into the question". Only $25 \%$ of students gave the expected answer "no". It appears that students at this stage were not clear how much they needed to rely on sources and how much should be their own original thinking on a subject. It is also worth noting that only $75 \%$ of students who responded believed the essay was used to show they had read widely on the subject.

One area for concern related to the task on characteristics of a successful essay, where $40 \%$ indicated that complex academic language was not required in a successful essay. Only $50 \%$ of the respondents correctly identified that it was not always appropriate. The responses of a majority of students indicate that they understand the need to use evidence from literature to support points and apply key theories. According to results in this task an overwhelming $98 \%$ of students were aware before arriving at university that they had to reference all the material they used 
from literature and other sources. The difference between this answer and the results from the online survey where only half of respondents claimed to understand plagiarism and academic integrity before starting university may be due to linking the two together indicating that students did not fully appreciate the close relationship of both things.

As discussed earlier in this paper, when faced with different examples of a paragraph from a given source students found it very difficult to distinguish between 'flagrant' plagiarising, direct copying with referencing, paraphrasing but no references, inadequate paraphrasing with referencing, paraphrasing and referencing and direct quotation and referencing. It was clear that many students were not aware that plagiarism takes many forms, is not black and white, and is not simply copying directly from a given text or website.

According to the survey results over $75 \%$ of students feel that they have a better understanding of the importance of academic excellence as a result of the study skills exercises. The survey results indicate that we need to provide more information and tasks relating to students' understanding of critical thinking as just over $45 \%$ agreed that the study skills helped in this area. Survey results have also shown that students really value the relationship with their Level 1 academic tutor but their biggest source of help is the written feedback they receive on their essays.

\section{Staff perspective}

The staff found a significant difference in the engagement of students in tutorials compared with previous years. Students were better prepared and more willing to contribute from the outset. Initial worries from students that they were being tested in the study skills were quickly dealt with in a sensitive manner.

Staff reported that essay content and structure had generally improved on previous years with far fewer basic mistakes in referencing. It was also noted that there was much more evidence of critical thinking and detailed discussion of the key themes, with evidence of wider reading having been done. Staff appreciated the time saved in not having to prepare for any plagiarism panels.

It will be interesting to follow this cohort through their full degree programme to determine if the initial findings of this pilot project translate to improved degree results.

\section{Conclusion and suggestions for further study}

As Macdonald and Carroll (2006) argue, promoting sound, defensible and scholarly academic practices is far more productive than channelling energy into methods of detection and punishment. The findings from this pilot project are absolutely in agreement with this argument. Higher education institutions are finding themselves under increasing pressure to address the causal issues relating to plagiarism, rather than simply responding to these with robust strategies to deal with the unfortunate after-effects.

Overall this pilot project has been a resounding success, as feedback from students and postgraduate tutors has demonstrated. Whilst there are students who have not been positive in terms of their formal feedback, we would contend that many of these students are either the small percentage who have had a very strong lead from their previous experience in school and/or are very able students to begin with (Group 1), or those Group 3 students who are unable/unwilling to engage in the necessary steps to ensure a successful transition from school- to university-level study. In other words, it is impossible to satisfy everyone due to varied previous experience.

Results indicate that the majority of students have really profited from their 
engagement with the pre-arrival tasks and the associated tutorial sessions and have an understanding of the expectations of their new department from a very early stage in their University career. However, careful monitoring by staff of those students who have not yet grasped the basic concepts will be required to ensure they do not fall behind.

Survey results have shown that students strongly value the relationship with their Level 1 academic tutors, and still put most value on the written feedback they receive on their essays. This may indicate that many still yearn for the 'spoon feeding' of previous educational experience and this expectation is anticipated to be reinforced when students pay increased fees (from October 2012). Thus, there is a continued challenge for staff to get the balance right with online material supplementing and supporting - and not replacing - face to face contact.

Whilst this paper has provided evidence to demonstrate the obvious success of the pre-arrival study skills, statistical analysis of grade classifications on submitted essays have not increased significantly. We believe this can be attributed to reluctance from some markers to award exceptionally high marks at the top end of our approved marking scale (which is deliberately designed to stretch grades at the top and bottom end and reward exceptional work accordingly). This is evidenced in Department Education Committee and Board of Examiners minutes and is currently under review. Additionally, this project will follow the students through to their final degree classification in two years time which will provide a more accurate guide to performance.

In the next academic year the pre-arrival study skills tasks will be built into all Level 1 compulsory modules but there is a need to manage student expectations better by providing more scaffolding prior to starting the tasks. This will involve more information in the instructions provided to students with regard to the amount of time they should spend in total on the tasks, a range of minimum and maximum words required in free text answers and much more emphasis on explaining the change from directed to self-directed study.

Future developments and initiatives may involve a more concerted attempt to situate the tasks within the framework of belonging to an academic community of practice; with greater emphasis on deep learning and the social/non-formal aspects of studying. Introducing tasks where there is interaction between the cohort such as commenting on a short extract collaboratively either within the online learning environment or on a social networking site is under consideration.

\section{References}

Angelini, M. (2007). Evaluation of the practice and effectiveness of University College London's transition programme, 10th Pacific Rim First Year in Higher Education Conference 2007, Brisbane, 4-6 ${ }^{\text {th }}$ July 2007. Retrieved March 8, 2012, from http://www.fyhe.com.au/past papers/papers07/final papers/pdfs/3b.pdf

Biggs, J., \& Tang, C. (2007). Teaching for quality learning at university. Open University Press. Retrieved March 28, 2012, from: http://lib.myilibrary.com? $\mathrm{ID}=133106$

Crabtree, H. (2006). The impact of student centred learning: An evaluation of tutor and student experiences', $3^{\text {rd }}$ Education in a Changing Environment Conference, University of Salford, $12-13^{\text {th }}$ January 2006. Retrieved March 24, 2012, from www.ece.salford.ac.uk/proceedings/papers/hc 06.ttf

Crabtree, H., Roberts, C., \& Tyler, C. (2007). Understanding the problems of transition into higher education', $4^{\text {th }}$ Education in a Changing Environment Conference, University of Salford, $13-14^{\text {th }}$ September 2007. Retrieved March 6, 2012, from http://www.ece.salford.ac.uk/proceedings/papers/35 07.pdf 
De Schutter, O. (2011). Food crises: Five priorities for G20. Poverty Matters Blog, 16 June 2011. Retrieved September 24, 2011, from http://www.guardian.co.uk/ global-development/poverty-matters/2011/jun/16/food-crises-five-priorities-g20.

Harvey, L., \& Drew, S. (2006). The first-year experience: A review of literature for the Higher Education Academy. Retrieved March 20, 2012, from http:// www.heacademy.ac.uk/assets/documents/archive/ first year experience exec summary.pdf

Lightfoot, L. (2006, February 9). 'Spoon-fed' pupils can't cope at college. Telegraph. Retrieved March 6, 2012, from http://www.telegraph.co.uk/news/ uknews/1510020/Spoon-fed-pupils-cant-cope-at-college.html

Macdonald, R., \& Carroll, J. (2006). Plagiarism - a complex issue requiring a holistic institutional approach. Assessment \& Evaluation in Higher Education, 31(2), 233-245. Retrieved March 7, 2012, from http:// dx.doi.org/10.1080/02602930500262536

Moore, S., Neville, C., Murphy, M., \& Connolly, C. (2010). The ultimate study skills handbook. Open University Press. Retrieve March 8, 2012, from http:// lib.myilibrary.com?ID $=333849$

Park, C. (2004). Rebels without a cause: towards an institutional framework for dealing with plagiarism by students. Journal of Further and Higher Education, 28(3), 291-306. Retrieved March 8, 2012, from http:// dx.doi.org/10.1080/0309877042000241760

Smith, L. (2010). StudyLink: A case study of an enabling programme supporting the transition to the first year of University. First Year in Higher Education Conference, Queensland University of Technology, June 2010. Retrieved January 19, 2012, from http://www.fyhe.com.au/past papers/papers10/content/ pdf/4A.pdf

\section{Acknowledgements}

\section{Geography Department}

Professor Peter Atkins and Professor Mike Bentley (Module Convenors)

Jo Cairns and Carly Maynard (Research Postgraduate liaison)

Dr Nick Cox (STATA analysis)

Sean Knox (Postgraduate Tutor)

\section{Level 1 Geography Students}

\section{English Language Centre}

Louise Greener and Dr Philip Nathan for work based on their research

Nathan, P.B. (2007) 'Teaching against plagiarism in the EAP classroom', in B. Beaven (ed.) IATEFL 2006 Harrogate Conference Selections. Canterbury: IATEFL p.102

\section{University Library}

Richard Pears 


\section{About the authors}

Judith Jurowska has worked at Durham University in the UK for 11 years, the past 6 of those as a learning technologist responsible for assisting academics to get the most out of the VLE and promoting eLearning across the institution. Judith is a Fellow of the Higher Education Academy and a Certified Member of the Association of Learning Technologist in the United Kingdom. Judith's interests are in promoting academic integrity and plagiarism avoidance throughout the university.

John Thompson has worked at Durham University for 12 years, as both a teaching fellow and Undergraduate Programme Coordinator in the Geography Department. John has a background in the geographies of organised labour and has teaching experience in economic geography and social scientific research methods. More recently John has developed an interest in learning technologies and in particular the interface between the VLE and social networks. John has trialled the combined use of plagiarism detection software and the promotion of academic integrity amongst undergraduate students. 